\title{
Indicators to address climate change impacts on marine ecosystems
}

\author{
Lisa Maddison', I. van Putten² and F. Zuo ${ }^{3}$ \\ IMBER ClimEco4 summer school, Shanghai, China, 4-9 August 2014
}

\begin{abstract}
Summer schools are an important capacity building activity for Integrated Marine Biogeochemistry and Ecosystem Research (IMBER; www.imber.info), a sister project of PAGES in the International GeosphereBiosphere Programme. Summer schools provide training for students and early-career researchers in some of the techniques and methods used in IMBER's cutting-edge research. The training also aims to equip young researchers to work in interdisciplinary teams and address global issues in coastal and marine socio-ecological systems. The fourth in the ClimEco (Climate and Ecosystems) summer school series, ClimEco4, focused on defining and constructing biophysical, social, and economic indicators for evaluating marine ecosystems and using them to inform policy and decision-making.
\end{abstract}

Twenty-four lectures were given by international experts and live-streamed from the East China Normal University's live channel. These were followed by group exercises in which modeling and statistical techniques were applied to real-world socio-ecological data. Group projects were presented at the end of the summer school. Participants also had the opportunity to showcase their own research during a poster session.

To bring everyone up to speed, the first set of lectures introduced relevant terminology and concepts. Then climate change issues and impacts on marine ecosystems from biophysical, socio-economic and governance perspectives were discussed. This was followed by a general overview of indicators; what they are and how and where they are used (Box 1). Next, the use of indicators to examine climate change and marine biogeochemistry at different time scales was outlined. Eric Galbraith from McGill University, Canada provided the paleo perspective and gave an entertaining depiction of the history of the Earth occurring within a single calendar year (view the YouTube video).

The next set of lectures focused on acquiring, accessing, and analysing data including quality control and nonlinearity exploration, such as detecting "tipping points" and developing decision criteria. Statistical techniques, data sharing, and

\section{Simple indicators}

- Biomass of functional groups e.g. piscivores, omnivores, zoopiscivores, benthivores, detritivores

- Sea surface temperature, $\mathrm{pCO}_{2^{\prime}}$, salinity, nitrate

- Number of fishery jobs, average wage, average price of fish

\section{Complex indicators}

- Stoichiometric ratios e.g. Redfield ratio (C:N:P=106:16:1)

- Large Fish Indicator (LFI), Large Species Indicator (LSI)

- Proportion of predatory fish in the community

- Pelagic : demersal ratio

- Landed value/GDP

- Average fisheries wage/average national wage

\section{Even more complex indicators}

- Shannon index of diversity

- Pielou's species evenness

- 4D Ecosystem exploitation index

- Slope of the biomass spectrum

- Ocean Health Index

Box 1: Examples of simple, complex, and even more complex indicators used to summarize complex and often disparate datasets.

approaches on publishing and reusing scientific data were also discussed.

Case studies were used to illustrate how coastal communities and socio-economic indicators can be linked to marine ecosystems and socio-ecological models. The importance of assessing the performance of indicators, their precision, and statistical power was also discussed.

The final lectures outlined the use of economic and social indicators for policy and decision-making, and, in particular, fisheries management. Participants discussed the advantages of knowing how to communicate the salient information the indicators provide to a range of different audiences.

The week ended with group project presentations, enabling participants to apply the theory and practical learning they had acquired. Using techniques and methods covered in the lectures, participants were tasked with analysing a real-world dataset comprising a socio-ecological system. Several participants brought their own data, which they augmented with other data sourced from the Internet. Each group undertook a socio-ecological analysis and reported on the state of the system and the management tradeoffs. The project results, including potential entry points for system management, were presented to a panel of "managers", who provided feedback.

By all accounts, ClimEco4 was a great success, and participants came away equipped with the knowledge of how to source, analyze, and transform data into usable products, tools, or advice. In addition to the training, and perhaps even more beneficial, were the opportunities the course offered for networking and interacting with both established research ers and with their peers from a variety of different scientific disciplines. Linkages like these are essential for fostering interdisciplinary and collaborative science in the future.

The ClimEco4 summer school lectures can be viewed on the IMBER International Project Office's YouTube channel at: www.youtube.com/channel/UCinzjRz7_ TKHESn6uggCKIw or the Dailymotion channel at: www.dailymotion.com/user/ IMBER_IPO/1

\section{ACKNOWLEDGEMENTS}

We are very grateful for the generous sponsorship from PAGES that provided travel support for two participants to attend the summer school.

\section{AFFILIATIONS}

IIMBER International Project Office, Institute of Marine Research, Bergen, Norway

${ }^{2}$ Commonwealth Scientific and Industrial Research Organisation (CSIRO), Hobart, Australia

${ }^{3}$ IMBER Regional Project Office, East China Normal University, Shanghai, China

\section{CONTACT}

Lisa Maddison: Lisa.Maddison@imr.no 